\title{
The Novel cPLA2 Inhibitor AK106-001616 Has a Protective Effect on SOD1693A-Induced Cell Death in NSC34 Murine Motor Neuron-Like Cell
}

\author{
Kazuki Ohuchi', Kazuhiro Tsuruma1, Masamitsu Shimazawa', Junji Nakamura², \\ Hideaki Hara ${ }^{*}$ \\ ${ }^{1}$ Molecular Pharmacology, Department of Biofunctional Evaluation, Gifu Pharmaceutical University, \\ Gifu, Japan \\ ${ }^{2}$ Asahi Kasei Pharma Corporation, Tokyo, Japan \\ Email: "hidehara@gifu-pu.ac.jp
}

Received 15 April 2016; accepted 20 May 2016; published 23 May 2016

Copyright (C) 2016 by authors and Scientific Research Publishing Inc.

This work is licensed under the Creative Commons Attribution International License (CC BY). http://creativecommons.org/licenses/by/4.0/

(c) (i) Open Access

\section{Abstract}

The expression of cytosolic phospholipase A2 (cPLA2) expression is up-regulated in animal model of ALS and in patients with familial amyotrophic lateral sclerosis (fALS). Inhibition of cyclooxygenase 2 (COX2), which is a downstream enzyme of cPLA2, ameliorates the impairment of motor function in the ALS model mice. Therefore, the arachidonic acid cascade, including the cPLA2COX2 pathway, is an important therapeutic target of ALS. The current study was designed to investigate the potential of AK106-001616, an inhibitor of CPLA2, in protection of motor neuron cell death induced by mutant superoxide dismutase (SOD1 $\left.{ }^{\mathrm{G} 93 A}\right)$. AK106-001616 (1 - $\left.10 \mu \mathrm{M}\right)$ protected

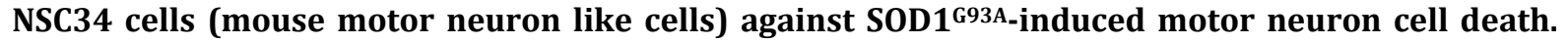

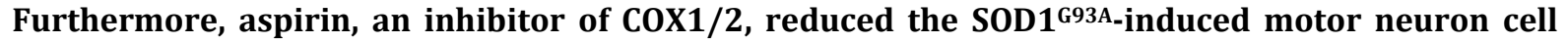
death at a concentration that inhibited COX2. Celecoxib, a selective COX2 inhibitor, also reduced the SOD1 ${ }^{\mathrm{G} 93 \mathrm{~A}}$-induced motor neuron cell death. These results suggest that the arachidonic acid

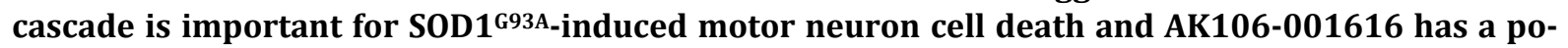
tent neuroprotective effect against it. AK106-001616 may be a useful therapeutic agent against SOD1 ${ }^{\text {G93A-induced ALS. }}$

\section{Keywords}

AK106-001616, Amyotrophic Lateral Sclerosis, cPLA 2 , NSC34, SOD1 ${ }^{\text {G93A }}$

How to cite this paper: Ohuchi, K., Tsuruma, K., Shimazawa, M., Nakamura, J. and Hara, H. (2016) The Novel cPLA2 Inhibitor AK106-001616 Has a Protective Effect on SOD1 ${ }^{\text {G93A }}$-Induced Cell Death in NSC34 Murine Motor Neuron-Like Cell. Pharmacology \& Pharmacy, 7, 193-199. http://dx.doi.org/10.4236/pp.2016.75025 


\section{Introduction}

Amyotrophic lateral sclerosis (ALS) is a neuromuscular disorder characterized by the degeneration of spinal motor neurons [1]. Riluzole and edaravone are used for the treatment of ALS in Japan, but these drugs have limited effects and only slightly prolong life of the patients. The mutation of superoxide dismutase $1^{\text {G93A }}$ (SOD1 $^{\text {G93A }}$; glycine residue 93 of SOD1 changes to alanine) causes familial ALS (fALS) [2]. In SOD1 ${ }^{\mathrm{G} 93 \mathrm{~A}}$ transgenic mice, there is a motor neuron loss from the spinal cord followed by paralysis in one or more limbs; they serve as a model for ALS [3]-[6].

Cytosolic phospholipase A2 (cPLA2) serves as a starting point for the arachidonic acid cascade. It catalyzes the release of arachidonic acid from cell membranes that result in the release of inflammatory mediators such as prostaglandins and leukotrienes, which are synthesized downstream of arachidonic acid cascade [7].

There have been some reports of cPLA2 involvement in ALS pathology. For example, the expression of CPLA2 at the protein and mRNA level was elevated in the spinal cord of SOD1 ${ }^{\mathrm{G} 93 \mathrm{~A}}$ mice [8] [9]. Furthermore, the involvement of COX2 and prostaglandin 2 (PGE2) which are downstream molecules of cPLA2, in ALS pathology has also been actively studied. For instance, the expression of PGE2 was elevated in the spinal cord of SOD1 ${ }^{\text {G93A }}$ mice; the administration of a COX2 inhibitor, celecoxib and refecoxib, extended the survival times of these mice [10]. In addition, PGE2 induced cell death in NSC34 cell murine motor neuron cell line [11]. Therefore, cPLA2-COX2-PGE2 pathway may be an important therapeutic target for ALS.

AK106-001616 was synthesized as a novel cPLA2 inhibitor and the combination therapy with methotrexate was reported to be effective on rheumatoid arthritis patient [12]. The present study focused on the arachidonic acid cascade and evaluated the neuroprotective effect of AK106-001616 [12] against SOD1 ${ }^{\mathrm{G} 93 \mathrm{~A}}$-induced motor neuron cell death.

\section{Materials and Methods}

\subsection{Materials}

AK106-001616 was gifted from Asahi Kasei Pharma Corporation (Tokyo, Japan). Aspirin and celecoxib were purchased from Cayman chemical company (Ann Arbor, MI, US) and Abcam (Cambridge, UK) respectively.

\subsection{Cell Cultures}

The murine motor neuron cell line, NSC34 was maintained in Dulbecco's modified Eagle’s medium (DMEM; Nacalaitesque, Kyoto, Japan) containing 10\% fetal bovine serum (FBS), 100 units/mL penicillin (Meiji Seika Kaisha Ltd., Tokyo, Japan), and $100 \mu \mathrm{g} / \mathrm{mL}$ streptomycin (Meiji Seika) in a humidified 95\% air and 5\% $\mathrm{CO}_{2}$ atmosphere at $37^{\circ} \mathrm{C}$. Cells were passaged by trypsinization every 2 or 3 days, and maintained in a 10 -cm cell culture dishes (BD Biosciences, Franklin Lakes, NJ, USA).

\subsection{Cell Death Assay}

NSC34 cells were seeded at a density of $7 \times 10^{3}$ cells per well into 96-well plates (BD Biosciences). After incubation, cells were transfected with EGFP-SOD1 ${ }^{\text {G93A }}$ plasmid vectors for $6 \mathrm{~h}$ using Lipofectamine 2000 (Thermo Fisher Scientific K.K., Waltham, MA, USA) in OptiMEM. After transfection, the cell culture medium was replaced with fresh DMEM containing 10\% FBS and the cell were cultured for $42 \mathrm{~h}$. Subsequently, culture medium was replaced with serum-free DMEM or DMEM containing 1\% FBS, AK106-001616 (1, 3 and $10 \mu M)$, aspirin (1, 10, 100 and $10000 \mu \mathrm{M})$ and celecoxib (0.05, $0.5 \mu \mathrm{M}$ ) (dissolved in PBS containing less than 1\% DMSO).

Nuclear staining assays were carried out $27 \mathrm{~h}$ after serum deprivation. Cell death rate was assessed by combination staining with Hoechst 33342 (Thermo Fisher Scientific K.K) and propidium iodide (PI; Thermo Fisher Scientific K.K). Images were captured using an inverted epifluorescence microscope (IX70; Olympus. Co., Tokyo, Japan). The number of cells per condition was counted with an image-processing software (Image-J, version $1.33 \mathrm{f}$; National Institutes of Health, Bethesda, MD, USA). PI-positive cells rates were calculated as reported previously (Shimazawa et al., 2010).

\subsection{Statistical Analysis}

Data were presented as means \pm S.E.M. Statistical comparisons were made using two-tailed $t$-test or one-way 
analysis of variance ANOVA followed by Dunnett's test; $\mathrm{P}<0.05$ was considered to indicate a statistical significance.

\section{Results}

\subsection{AK106-001616 Protects NSC34 Cells against SOD1G93A-Induced Motor Neuron Cell Death}

The effect of AK106-001616 against SOD1 ${ }^{\mathrm{G} 93 \mathrm{~A}}$-induced motor neuron cell death was evaluated by using combination staining with Hoechst 33342 and PI (representative images are shown in Figure 1(a)). Hoechst 33342 stains both alive and dead cells, whereas PI stains the dead cells only. As shown in Figure 1(b), AK106-001616 reduced the SOD1 ${ }^{\mathrm{G} 93 \mathrm{~A}}$-induced motor neuron cell death in a concentration-dependent manner (from 3 - $10 \mu \mathrm{M}$ ).

\subsection{COX2 Selective Inhibition Protects NSC34 Cells against SOD1 ${ }^{\text {G93A-Induced Motor }}$ Neuron Cell Death}

To confirm that the inhibition of arachidonic acid cascade leads to the neuroprotection, the effect of aspirin against SOD1 ${ }^{\text {G93A }}$-induced motor neuron cell death was evaluated by combination staining with Hoechst 33342 and PI (Figure 2(a)). Aspirin did not reduce the SOD $1^{\mathrm{G} 93 \mathrm{~A}}$-induced motor neuron cell death from 1 to $10 \mu \mathrm{M}$ (Figure 2(b)), however, it showed neuroprotective effects against the SOD $1{ }^{\mathrm{G} 93 \mathrm{~A}}$-induced motor neuron cell death from 100 to $1000 \mu \mathrm{M}$ (Figure 2(b)). The effects of celecoxib against SOD $1^{\mathrm{G} 93 \mathrm{~A}}$-induced motor neuron cell death were also evaluated in the same way (Figure 3(a)). It reduced SOD $1{ }^{\mathrm{G} 93 \mathrm{~A}}$-induced motor neuron cell death at 0.5 to $5 \mu \mathrm{M}$ (Figure 3(b)).

\section{Discussion}

The present study was designed to evaluate the protective effects of AK106-001616, a cPLA2 inhibitor [12],

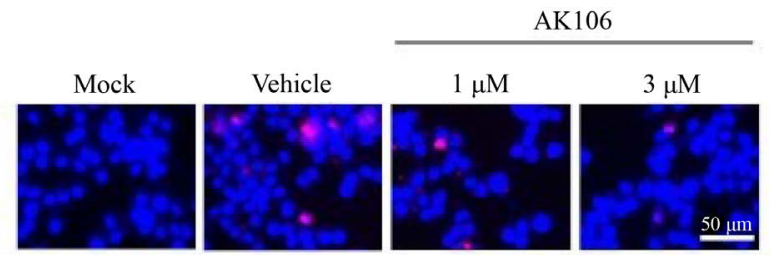

(a)

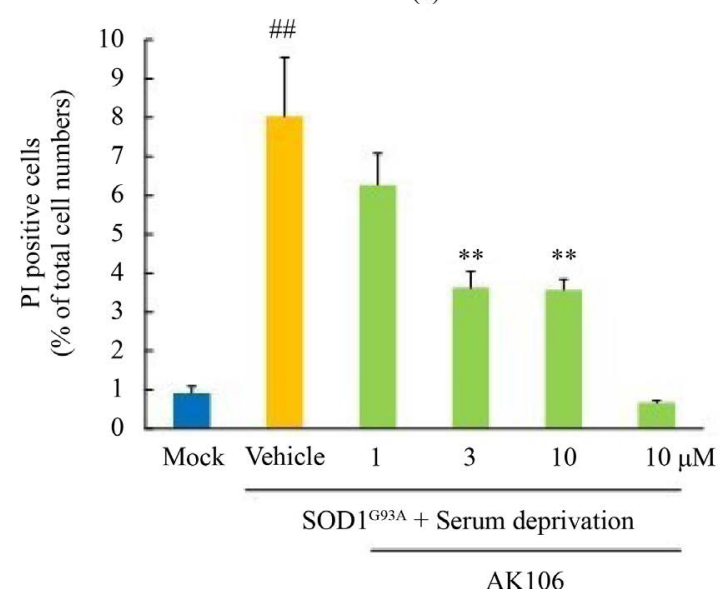

(b)

Figure 1. AK106-001616 protects NSC34 cells against SOD1 ${ }^{\text {G93A }}$-induced motor neuron cell death. (a) Representative fluorescence images of SOD1 ${ }^{\mathrm{G} 93 \mathrm{~A}}$-transfected NSC34 cells stained with Hoechst 33342 (blue) and propidium iodide (PI: red) after $27 \mathrm{~h}$ serum deprivation and treatment with or without AK106-001616. The images were captured using 10× objective lens. Scale bar shows $50 \mu \mathrm{m}$. (b) The quantitative analysis of the ratio of PI positive cells to Hoechst 33342 positive cells treated with or without AK106-001616. Each column and bar represents mean \pm S.E.M. $(\mathrm{n}=4) .{ }^{\#}, \mathrm{P}<0.01$ versus Mock (empty vector, Student's $t$-test). ${ }^{*}, \mathrm{P}<0.05 ;{ }^{* *}, \mathrm{P}<0.01$ versus vehicle (Dunnett's test). 


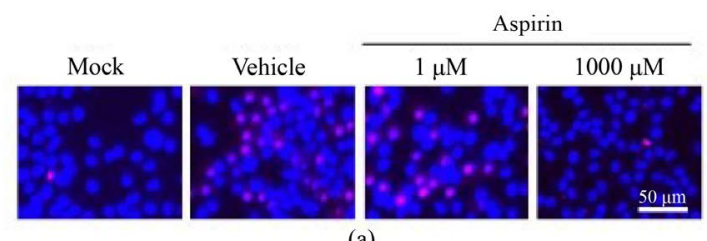

(a)

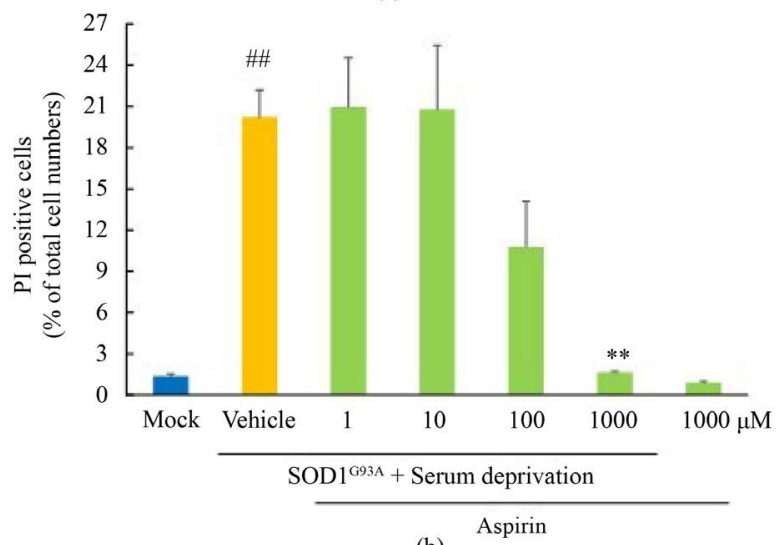

(b)

Figure 2. Aspirin does not protect NSC34 cells against SOD1 ${ }^{\mathrm{G} 93 \mathrm{~A}}$-induced motor neuron cell death. (a) Representative fluorescence images of SOD1 ${ }^{\mathrm{G} 93 \mathrm{~A}}$-transfected NSC34 cells stained with Hoechst 33342 (blue) and propidium iodide (PI: red) after $27 \mathrm{~h}$ serum deprivation and treatment with or without aspirin. The images were captured using $10 \times$ objective lens. Scale bar shows $50 \mu \mathrm{m}$. (b) The quantitative analysis of the ratio of PI positive cells to Hoechst 33342 positive cells treated with or without aspirin. Each column and bar represents mean \pm S.E.M. $(\mathrm{n}=6) .{ }^{\#}, \mathrm{P}<0.01$ versus Mock (empty vector, Student's $t$-test). ${ }^{*}, \mathrm{P}<0.05 ;{ }^{* *}, \mathrm{P}<0.01$ versus vehicle (Dunnett's test).

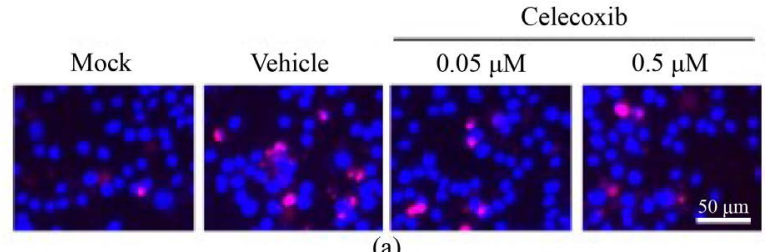

(a)

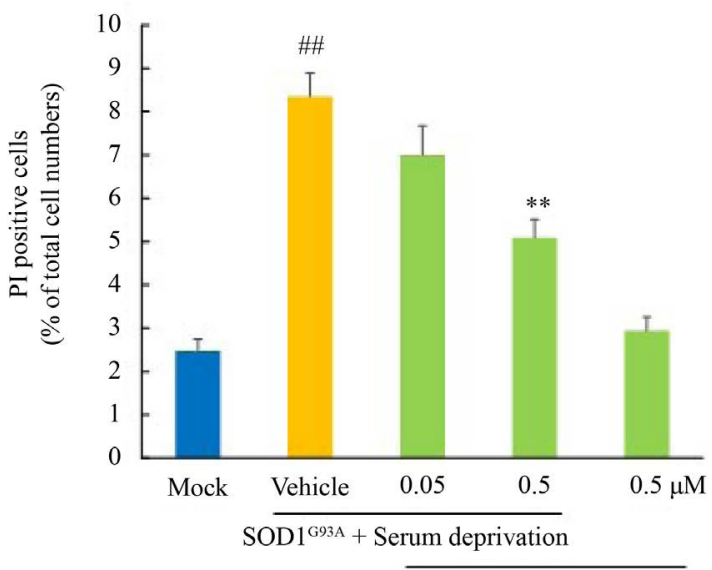

(b)

Figure 3. Celecoxib protects NSC34 cells against SOD1 ${ }^{\mathrm{G} 93 \mathrm{~A}}$-induced motor neuron cell death. (a) Representative fluorescence images of SOD1 ${ }^{\mathrm{G} 93 \mathrm{~A}}$-transfected NSC34 cells stained with Hoechst 33342 (blue) and propidium iodide (PI: red) after $27 \mathrm{~h}$ serum deprivation and treatment with or without celecoxib. The images were captured using $10 \times$ objective lens. Scale bar shows $50 \mu \mathrm{m}$. (b) The quantitative analysis of the ratio of PI positive cells to Hoechst 33342 positive cells treated with or without celecoxib. Each column and bar represents mean \pm S.E.M. $(n=6) .{ }^{\# \#}, \mathrm{P}<0.01$ versus Mock (empty vector, Student's $t$-test). ${ }^{*}, \mathrm{P}<0.05 ;{ }^{* *}, \mathrm{P}<0.01$ versus Vehicle (Dunnett's test). 
against SOD ${ }^{\mathrm{G} 93 \mathrm{~A}}$-induced motor neuron cell death in NSC34 cell line. In the cell death assay using PI and Hoechst 33342, AK106-001616 showed a neuroprotective effect at 3 to $10 \mu \mathrm{M}$ (Figure 1(a) \& Figure 1(b)). The protective effects of aspirin and celecoxib were evaluated to confirm the contribution of the arachidonic acid cascade to SOD1 ${ }^{\mathrm{G} 93 \mathrm{~A}}$-induced motor neuron cell death. Aspirin is a non-selective COX1 and COX2 inhibitor ( $\mathrm{IC}_{50}$ is $3.57 \mu \mathrm{M}$ and $29.3 \mu \mathrm{M}$, respectively) [13], whereas celecoxib is a selective COX2 inhibitor ( IC $_{50}$ is 0.04 $\mu \mathrm{M})$ [14]. In this study, aspirin did not inhibit the motor neuron cell death at 1 to $10 \mu \mathrm{M}$, however, it inhibited the motor neuron cell death at concentrations higher than its $\mathrm{IC}_{50}$ for COX2 inhibition (Figure 2(a) \& Figure 2(b)) [15]. Furthermore, $0.5 \mu \mathrm{M}$ celecoxib significantly inhibited the motor neuron cell death (Figure 3(a) \& Figure 3(b)). Therefore, it can be suggested that the inhibition of COX2 is more important than the inhibition of COX1 in the protection of SOD1 ${ }^{\mathrm{G} 93 \mathrm{~A}}$-induced motor neuron cell death. These results showed that the inhibition of CPLA2 and COX2 contributes to the suppression of SOD ${ }^{\mathrm{G} 93 \mathrm{~A}}$-induced motor neuron cell death. Furthermore, the arachidonic acid cascade including CPLA2 and COX2 is important for the SOD1 ${ }^{\mathrm{G} 93 \mathrm{~A}}$-induced motor neuron cell death.

Previous studies have shown that the inhibition of cPLA2 leads to a neuroprotective effect in the in vitro Alzheimer's disease and Parkinson's disease models [16] [17] It was also shown that the expression of cPLA2 is increased in sporadic ALS and fALS patients [18], and in SOD1 ${ }^{\mathrm{G} 93 \mathrm{~A}}$ mice [8] [9]. Furthermore, activated cPLA2 deteriorates various pathogeneses of neurodegenerative diseases such as the neuronal excitatory synapses secretion, nitrosative stress, apoptosis and inflammatory reactions [17] [19]-[23]. It is suggested that the activated cPLA2 stimulates some signaling pathways following activation of the production of the protein kinases [24] and the reactive oxygen species (ROS) [25].

Studies that use COX2-targeting as therapeutic strategy have been actively conducted to investigate the pathology of ALS. For example, the administration of various COX2 inhibitors such as sulindac, nimeslide and celecoxib extended the survival times of SOD $1{ }^{\mathrm{G} 93 \mathrm{~A}}$ mice and suppressed the loss of neuronal cells in the spinal cord of SOD1 ${ }^{\text {G93A }}$ mice [8] [10] [26] [27]. However, findings of these clinical reports are not consistent with the expression of cPLA2 and COX2. In fALS patients, the expression of both CPLA2 and COX2 was increased, however, in sporadic ALS patients, the expression of COX2 had no change, although the cPLA2 expression was increased [8]. Furthermore, celecoxib had no effect on muscle strength, vital capacity and motor unit number of ALS patient [28]. Taken together, it can be proposed that the cPLA2 inhibition could be a more effective therapeutic target in ALS treatment than COX2 inhibition.

\section{Conclusion}

In conclusion, AK106-001616 shows a neuroprotective effect on SOD ${ }^{\mathrm{G} 93 \mathrm{~A}}$-induced motor neuron cell death in NSC34 cells through inhibition of p-cPLA2 expression. Furthermore, AK106-001616 may be a useful therapeutic agent against SOD1 ${ }^{\text {G93A }}$-induced fALS.

\section{References}

[1] Pasinelli, P. and Brown, R.H. (2006) Molecular Biology of Amyotrophic Lateral Sclerosis: Insights from Genetics. Nature Reviews Neuroscience, 7, 710-723. http://dx.doi.org/10.1038/nrn1971

[2] Rosen, D.R., et al. (1999) Mutations in Cu/Zn Superoxide Dismutase Gene Are Associated with Familial Amyotrophic Lateral Sclerosis. Nature, 362, 59-62. http://dx.doi.org/10.1038/362059a0

[3] Gurney, M.E., et al. (1994) Motor Neuron Degeneration in Mice That Express a Human Cu,Zn Superoxide Dismutase Mutation. Science, 264, 1772-1775. http://dx.doi.org/10.1126/science.8209258

[4] Wong, P.C., et al. (1995) An Adverse Property of a Familial ALS-Linked SOD1 Mutation Causes Motor Neuron Disease Characterized by Vacuolar Degeneration of Mitochondria. Neuron, 14, 1105-1116. http://dx.doi.org/10.1016/0896-6273(95)90259-7

[5] Bruijn, L.I., et al. (1997) ALS-Linked SOD1 Mutant G85R Mediates Damage to Astrocytes and Promotes Rapidly Progressive Disease with SOD1-Containing Inclusions. Neuron, 18, 327-338. http://dx.doi.org/10.1016/S0896-6273(00)80272-X

[6] Ripps, M.E., Huntley, G.W., Hof, P.R., et al. (1995) Transgenic Mice Expressing an Altered Murine Superoxide Dismutase Gene Provide an Animal Model of Amyotrophic Lateral Sclerosis. Proceedings of the National Academy of Sciences of the United States of America, 92, 689-693. http://dx.doi.org/10.1073/pnas.92.3.689

[7] Kudo, I. and Murakami, M. (2002) Phospholipase A2 Enzymes. Prostaglandins \& Other Lipid Mediators, 68-69, 3-58. 
http://dx.doi.org/10.1016/S0090-6980(02)00020-5

[8] Kiaei, M., Kipiani, K., Petri, S., et al. (2005) Integrative Role of cPLA with COX-2 and the Effect of Non-Steriodal Anti-Inflammatory Drugs in a Transgenic Mouse Model of Amyotrophic Lateral Sclerosis. Journal of Neurochemistry, 93, 403-411. http://dx.doi.org/10.1111/j.1471-4159.2005.03024.x

[9] Almer, G., Guégan, C., Teismann, P., et al. (2001) Increased Expression of the Pro-Inflammatory Enzyme Cyclooxygenase-2 in Amyotrophic Lateral Sclerosis. Annals of Neurology, 49, 176-185. http://dx.doi.org/10.1002/1531-8249(20010201)49:2<176::AID-ANA37>3.0.CO;2-X

[10] Klivenyi, P., Kiaei, M., Gardian, G., et al. (2004) Additive Neuroprotective Effects of Creatine and Cyclooxygenase 2 Inhibitors in a Transgenic Mouse Model of Amyotrophic Lateral Sclerosis. Journal of Neurochemistry, 88, 576-582. http://dx.doi.org/10.1046/j.1471-4159.2003.02160.X

[11] Miyagishi, H., Kosuge, Y., Yoneoka, Y., et al. (2013) Prostaglandin E2-Induced Cell Death Is Mediated by Activation of EP2 Receptors in Motor Neuron-Like NSC-34 Cells. Journal of Pharmacological Sciences, 121, 347-350. http://dx.doi.org/10.1254/jphs.12274SC

[12] Kozaki, T., et al. (2015) Evaluation of Drug-Drug Interaction between the Novel cPLA2 Inhibitor AK106-001616 and Methotrexate in Rheumatoid Arthritis Patients. Xenobiotica, 45, 615-624. http://dx.doi.org/10.3109/00498254.2014.1000430

[13] Blanco, F.J., et al. (1999) Effect of Antiinflammatory Drugs on COX-1 and COX-2 Activity in human Articular Chondrocytes. The Journal of Rheumatology, 26, 1366-1373.

[14] Penning, T.D., et al. (1997) Synthesis and Biological Evaluation of the 1,5-Diarylpyrazole Class of Cyclooxygenase-2 Inhibitors: Identification of 4-[5-(4-Methylphenyl)-3-(trifluoromethyl)-1H-pyrazol-1-yl]benzenesulfonamide (SC-58635, celecoxib). Journal of Medicinal Chemistry, 40, 1347-1365. http://dx.doi.org/10.1021/jm960803q

[15] Jeong, J.K., et al. (2011) Prion Peptide-Mediated Cellular Prion Protein Overexpression and Neuronal Cell Death Can Be Blocked by Aspirin Treatment. International Journal of Molecular Medicine, 27, 689-693.

[16] Sanchez-Mejia, R.O., Newman, J.W., Toh, S., et al. (2008) Phospholipase A2 Reduction Ameliorates Cognitive Deficits in a Mouse Model of Alzheimer's Disease. Nature Neuroscience, 11, 1311-1318. http://dx.doi.org/10.1038/nn.2213

[17] Chalimoniuk, M., Stolecka, A., Ziemińska, E., et al. (2009) Involvement of Multiple Protein Kinases in cPLA2 Phosphorylation, Arachidonic Acid Release, and Cell Death in in Vivo and in Vitro Models of 1-Methyl-4-phenylpyridinium-Induced Parkinsonism-The Possible Key Role of PKG. Journal of Neurochemistry, 110, 307-317. http://dx.doi.org/10.1111/j.1471-4159.2009.06147.x

[18] Shibata, N., Kakita, A., Takahashi, H., et al. (2010) Increased Expression and Activation of Cytosolic Phospholipase A2 in the Spinal Cord of Patients with Sporadic Amyotrophic Lateral Sclerosis. Acta Neuropathologica, 119, 345-354. http://dx.doi.org/10.1007/s00401-009-0636-7

[19] Desbene, C., et al. (2012) Critical Role of cPLA2 in Abeta Oligomer-Induced Neurodegeneration and Memory Deficit. Neurobiology of Aging, 33, 1123, e17-e29.

[20] Last, V., Williams, A. and Werling, D. (2012) Inhibition of Cytosolic Phospholipase A2 Prevents Prion PeptideInduced Neuronal Damage and Co-Localisation with Beta III Tubulin. BMC Neuroscience, 13, 106.

http://dx.doi.org/10.1186/1471-2202-13-106

[21] Sundaram, J.R., Chan, E.S., Poore, C.P., et al. (2012) Cdk5/p25-Induced Cytosolic PLA2-Mediated Lysophosphatidylcholine Production Regulates Neuroinflammation and Triggers Neurodegeneration. The Journal of Neuroscience, 32, 1020-1034. http://dx.doi.org/10.1523/JNEUROSCI.5177-11.2012

[22] Fang, X.X., Jiang, X.-L., Han, X.-H., et al. (2013) Neuroprotection of Interleukin-6 against NMDA-Induced Neurotoxicity Is Mediated by JAK/STAT3, MAPK/ERK, and PI3K/AKT Signaling Pathways. Cellular and Molecular Neurobiology, 33, 241-251. http://dx.doi.org/10.1007/s10571-012-9891-6

[23] Kishimoto, K., et al. (2010) Cytosolic Phospholipase A2 Alpha Amplifies Early Cyclooxygenase-2 Expression, Oxidative Stress and MAP Kinase Phosphorylation after Cerebral Ischemia in Mice. Journal of Neuroinflammation, 7, 42.

[24] Sun, G.Y., Chuang, D.Y., Zong, Y.J., et al. (2014) Role of Cytosolic Phospholipase A2 in Oxidative and Inflammatory Signaling Pathways in Different Cell Types in the Central Nervous System. Molecular Neurobiology, 50, 6-14. http://dx.doi.org/10.1007/s12035-014-8662-4

[25] Shelat, P.B., Chalimoniuk, M., Wang, J.-H., et al. (2008) Amyloid Beta Peptide and NMDA Induce ROS from NADPH Oxidase and AA Release from Cytosolic Phospholipase A2 in Cortical Neurons. Journal of Neurochemistry, 106, 45-55. http://dx.doi.org/10.1111/j.1471-4159.2008.05347.x

[26] Pompl, P.N., Ho, L., Bianchi, M., et al. (2003) A Therapeutic Role for Cyclooxygenase-2 Inhibitors in a Transgenic Mouse Model of Amyotrophic Lateral Sclerosis. The FASEB Journal, 17, 725-727.

http://dx.doi.org/10.1096/fj.02-0876fje 
[27] Drachman, D.B., Frank, K., Dykes-Hoberg, M., et al. (2002) Cyclooxygenase 2 Inhibition Protects Motor Neurons and Prolongs Survival in a Transgenic Mouse Model of ALS. Annals of Neurology, 52, 771-778.

http://dx.doi.org/10.1002/ana.10374

[28] Cudkowicz, M.E., Shefner, J.M., Schoenfeld, D.A., et al. (2006) Trial of Celecoxib in Amyotrophic Lateral Sclerosis. Annals of Neurology, 60, 22-31. http://dx.doi.org/10.1002/ana.20903 